\title{
UTILIZAÇÃO DA PSICOMETRIA PARA AVALIAR A QUALIDADE DO SERVIÇO DE TRANSPORTE: UM ESTUDO DE CASO
}

\section{USE OF PSYCHOMETRICS TO EVALUATE THE QUALITY OF TRANSPORT SERVICE: A CASE STUDY}

\author{
Eloisa Maieski Antunes ${ }^{1}$; Fernanda Antonio Simões ${ }^{2}$ \\ ${ }^{1}$ Universidade Tecnológica Federal do Paraná - UTFPR - Curitiba \\ eloisa@utfpr.edu.br \\ ${ }^{2}$ Universidade Estadual de Maringá - UEM - Maringá \\ fasimoes@uem.br
}

\begin{abstract}
Resumo
Este trabalho tem por objetivo utilizar a psicometria como ferramenta para medir o nível de satisfação dos usuários de transporte urbano em relação à qualidade do sistema de transporte público urbano por ônibus. $O$ estudo foi aplicado no município de Maringá - PR. Os atributos avaliados foram: acessibilidade, tempo de viagem, lotação, pontualidade, sistema de informação, características dos veículos, comportamentos dos funcionários, segurança, confiabilidade, características das paradas de ônibus e satisfação geral e nos horários de pico. O instrumento de medida utilizado foi um questionário validado psicometricamente composto por 19 itens que avaliaram os atributos já citados, também foram coletados dados sobre sexo e renda da amostra. A análise de dados foi realizada através de técnicas psicométricas e da estatística descritiva. $O$ atributo que gera maior satisfação é a acessibilidade ao sistema de transporte público, o que gera maior insatisfação é em relação à lotação. A análise psicométrica indica que os itens podem ser agrupados em oito fatores, os quais explicam 68,77\% da variância. O Alfa de Cronbach é de 0,86 o que indica que o questionário apresenta consistência interna aceitável, ou seja, ele realmente mede o que se pretende medir, isso torna a pesquisa fidedigna.Conclui-se que este estudo contribui para conhecer as atitudes e a avaliação da população frente ao sistema de transporte local e para contribuir na disseminação de uma gestão mais eficiente. A metodologia proposta também pode ser utilizada em outros tipos de estudos que visam medir o nível de satisfação.
\end{abstract}

Palavras-chave: transporte público; prestação de serviço; mensuração.

\section{Introdução}

Nos últimos anos, a opinião do consumidor ganhou um espaço privilegiado na administração das corporações. A satisfação dos clientes é de suma importância porque está vinculada a imagem da empresa e a geração de lucro. As empresas que não buscam satisfazer as necessidades de seus clientes não conseguem sobreviver no mercado competitivo, por isso, os sistemas de mensuração da satisfação são reconhecidos pela sua importância administrativa e pelo 
seu caráter mercadológico e científico, pois oferecem uma importante contribuição às empresas como uma ferramenta auxiliar para traçar análises estratégicas, reconhecer mudanças necessárias em tempo hábil e indicar o melhor caminho para atingir as expectativas dos clientes, favorecendo ambos: o empresário porque o cliente vai utilizar os serviços e/ou produtos que são oferecidos, e o cliente porque estará satisfeito com o produto e/ou serviço prestado.

Uma das formas eficazes para avaliar o nível de atendimento das expectativas dos clientes é baseado nos métodos de avaliação qualitativa. Estes métodos são de amplo domínio das diversas áreas das ciências sociais e tem despertado profundo interesse nos engenheiros de produção e gestores da área de qualidade e de transporte. Portanto, quanto mais informações forem obtidas sobre a satisfação dos usuários do transporte coletivo por ônibus, maior a possibilidade de índices de qualidade nas empresas operadoras.

Os métodos de avaliação qualitativa são constituídos por um instrumento de medida que tem que ser coerente com o que se pretende medir. Como a qualidade é um conceito subjetivo, é preciso utilizar métodos consistentes que permitem este tipo de avaliação e que o resultado seja confiável e fidedigno. A psicometria, uma área da psicologia, que trata das questões de medidas psicológicas tem sido usada para medir eventos subjetivos, como a satisfação - um sentimento intrínseco e pessoal. Estes métodos utilizam processos estatísticos que fornecem informações extremamente úteis ao planejamento e melhoria da operação do transporte público em consonância com as expectativas e necessidades dos usuários.

Desta forma, este trabalho tem por objetivo avaliar a satisfação do usuário em relação à qualidade do sistema de transporte público urbano por ônibus. O questionário foi aplicado em uma amostra de 383 pessoas em uma cidade do Estado do Paraná. Os atributos avaliados foram: acessibilidade, tempo de viagem, lotação, pontualidade, sistema de informação, características dos veículos, comportamentos dos funcionários, segurança, confiabilidade, características das paradas de ônibus e satisfação geral e nos horários de pico.

\section{Desafios da gestão da qualidade no transporte público}

A qualidade pode ser medida através das características dos produtos ou serviços, finais ou intermediários da empresa, ela inclui não só a qualidade do produto ou serviço, mas também a qualidade da rotina da empresa, qualidade do treinamento, da informação, das pessoas, do sistema e dos objetivos. A família ISO 9000 é um exemplo apropriado para exemplificar os diversos tipos de certificação que é possível obter, basta definir o escopo que será auditado.

A qualidade está associada à satisfação e insatisfação com um determinado produto e/ou serviços. A satisfação ocorre quando um produto tem desempenho ou características superiores da esperada, já à insatisfação ocorre quando há deficiências no produto ou serviço. O resultado final da 
qualidade, sob o ponto de vista do cliente, é dado pelo balanço entre a expectativa, ao serviço prestado e a percepção que ele teve do sistema de transporte.

Serviços usados de forma rotineira, desde que tenham baixa variabilidade no nível de serviço, levam a expectativa mais próxima do real desempenho do sistema. Nos serviços em que o nível de expectativa é alto, desempenhos inadequados levam à insatisfação dos clientes e ao julgamento dos serviços como de baixa qualidade. Há situações em que os níveis de expectativa são tais, que podem vir a ser superados pelo desempenho percebido e alcançam à satisfação do cliente. Cabe destacar que é um processo dinâmico e que os níveis de expectativa ajustam-se rapidamente, em função da comunicação boca a boca e das experiências anteriores, assim, vai se formando a imagem de um dado serviço (LIMA JUNIOR, 1994). Todos os fatores são percebidos por todos os clientes diferentemente, portanto, pode ter o risco de não ser percebido corretamente o que foi realizado e ficarem insatisfeitos ou supervalorizarem os resultados.

A prestação de serviço do transporte público apresenta características diferentes das prestações de serviços mais comuns, como bancos e escritórios de contabilidade. Oliveira (2003) ressalta que a prestação dos serviços públicos, por ser essencial ao interesse coletivo, é regida por cinco princípios gerais: generalidade (serviço igual para todos); eficiência (atualização permanente do serviço e segurança para o usuário); modicidade (o valor da tarifa não deve ser oneroso demais); cortesia (o usuário deve ser tratado com urbanidade) e continuidade (o serviço deve ser permanentemente oferecido ao usuário).

É difundida a ideia que a demanda por transporte coletivo é cativa, associando-se a isso o conceito de que, independente da qualidade do serviço oferecido, os usuários continuarão usando o sistema. Porém, a demanda não é homogênea, existem usuários com diversas características sociais e econômicas, que utilizam o mesmo transporte por não haver outras opções. Assim, diversos passageiros podem encontrar um transporte público de má qualidade o que resulta conforme Massler (1994) em:

1. Desistência da realização da viagem;

2. Surgimento de sistema clandestino de transporte;

3. Realização a pé da viagem;

4. Realização de um modo privativo da viagem.

Cancado (1995) comenta que o estudo das necessidades dos usuários de transporte vem despertando interesse de diversos pesquisadores nas últimas décadas. O transporte é um instrumento que auxilia o homem a satisfazer seus desejos de deslocamentos próprios e de mercadorias, visando a realização de outras atividades. O transporte é considerado uma atividade-meio, ligando as demais atividades, uma viagem é realizada em função da necessidade que o indivíduo tem que participar de 
uma determinada atividade (trabalho, lazer, saúde), em um lugar específico. Portanto, dentro da necessidade específica de transporte existe uma série de necessidades fundamentais que serão satisfeitas ou não, de acordo com as condições dos usuários e com os tipos de serviço ofertados pelo sistema de transporte de cada localidade. A análise das necessidades de transporte requer a análise das ofertas do sistema de transporte e do usuário, observando-se hábitos e preferências, padrões de deslocamentos, atividades-fim, utilização dos serviços.

Vários estudos realizados anteriormente sobre qualidade na área de transportes tiveram o enfoque do processo de produção dos serviços, enfatizando medidas técnicas e a conformidade às especificações, e pouca ênfase foi dada em relação à satisfação dos usuários e a motivação dos empregados. Nos sistemas de transporte público, a preocupação com o usuário e seus anseios está sendo cada vez mais focada. Está ultrapassado o conceito tradicional estabelecido pela empresa prestadora do transporte que define a relação entre o serviço planejado e o serviço oferecido, sendo que o mais correto é a visão com o foco no cliente e definida como o serviço recebido em relação ao serviço almejado. A atividade de transportes não tem como resultado produção bens físicos tangíveis, na verdade o que se faz é agregar benefícios aos passageiros em termos de utilidade de tempo e de espaço. A importância do transporte no cotidiano das pessoas fica evidenciada pelo tempo gasto nos deslocamentos diários entre o local de moradia e de trabalho (RODRIGUES, 2006).

Diversos aspectos são contemplados pelos usuários na avaliação da qualidade dos sistemas de transporte público. No entanto, a percepção individual e conjunta desses fatores varia bastante em função da condição social e econômica, da faixa etária, sexo etc (FERRAZ, 1990). Outro aspecto importante deve ser ainda considerado nas pesquisas visando definir padrões genéricos de avaliação: o crescimento do grau de expectativa dos passageiros com a melhoria da oferta, o que significa serem as opiniões influenciadas pelas condições de transporte vigentes.

Outro ponto importante é que a qualidade tem sido vista mais como um condicionante a redução de custos das empresas do que uma meta a ser alcançada ou superada, tendo como necessidade a sobrevivência das empresas em virtude da estrutura de mercado vigente (RODRIGUES, 2006).

Um aspecto que também deve ser considerado em pesquisas de avaliação da qualidade é o crescimento do grau de expectativa dos passageiros com a melhoria da oferta (FERRAZ, 1990). A satisfação de ter conseguido um nível maior de conforto e rapidez nas suas viagens durará pouco tempo, pois o nível de aspiração está sempre além do nível alcançado. Assim, parece bastante lógico estabelecer a hipótese de que a natureza hedonista do homem, associada à aspiração, torna ilimitado o desejo de viajar de modo mais rápido e mais confortável (KAWAMOTO, 1987). 
Cabe acrescentar que um serviço de melhor qualidade implica em maiores taxas, sendo que se o público-alvo da empresa for constituído de pessoas com maior poder aquisitivo esse aumento torna-se insignificante, porém se o público for de pessoas com baixo poder aquisitivo é melhor ter tarifas baixas do que um serviço de melhor qualidade (FERRAZ, 1990). Apesar da problemática e dos conflitos de interesses é importante oferecer um sistema de transporte público que agrade a maioria dos usuários cativos.

Ribeiro Neto (2001), afirma que um transporte público por ônibus será bem sucedido se:

1. Atender uma necessidade, utilização ou aplicação bem definida;

2. Satisfazer a expectativa dos passageiros;

3. Atender a normas e especificações aplicáveis;

4. Atender a requisitos da sociedade;

5. Estejam a preços competitivos;

6. Tenham um bom suporte para manutenção das características de qualidade.

Martins, Aragão e Miazaki (1997) citam os fatores que afetam a avaliação do serviço de transporte coletivo:

1. Fatores externos: por exemplo, a cultura em que o usuário está inserido e as influências pessoais que são exercidas sobre ele, opinião da família ou de dos grupos que toma como referência positiva ou negativa para seu comportamento, propaganda boca a boca que chega a ele, as características do mercado de prestação de serviço de forma geral relacionadas à existência ou não de operadores alternativos, as características do mercado de prestação de serviço prestado pela operadora em particular, a postura e aparência dos empregados e dos demais usuários do serviço, ambiente físico das instalações de embarque e desembarque e dos veículos, preço relacionado às características do serviço, a comunicação sobre o serviço em todas as suas formas visual (oral e escrita) explicitando promessas de determinado nível de qualidade esperada, as demais formas de promoção do serviço, freqüência de ocorrência de situações de emergência ou de problemas relacionados ao serviço sob controle da operadora, ocorrência de catástrofes, greves ou situações fora do controle da operadora.

2. Fatores internos: psicográficos relacionados ao motivo da realização do deslocamento as atitudes sobre os serviços construídos.

\subsection{Medidas psicométricas}

Nos últimos anos, os pesquisadores de transporte têm demonstrado a importância de acrescentar medidas psicométricas aos seus estudos. Todo indivíduo tem um conjunto de necessidades físicas, sociais e psicológicas determinado pela situação real que ele assume na sua 
interação com as outras pessoas ou em grupos. Através de experiências passadas, os indivíduos desenvolvem consciência e formam-se atitudes que podem satisfazer as suas necessidades individuais ou coletivas. A percepção do objeto social, neste caso, a percepção da qualidade do transporte público por ônibus, é estabelecida por técnicas psicométricas num processo de agregação de fatores que formam atitudes; e conseqüentemente a preferência e a escolha do objeto (FARIA, 1985).

A psicometria busca explicar as probabilidades de ocorrência da conduta por meio de dados estatisticamente significativos. O instrumento de medida estabelecido psicometricamente é composto pelas seguintes etapas, a saber: a análise de itens, validade e fidedignidade do teste.

A análise dos itens visa estabelecer a compreensão dos itens e a pertinência dos mesmos ao atributo que pretende medir. Para que o questionário tenha um ótimo rendimento é necessário tomar alguns cuidados na redação dos itens, conforme sugere Abad et al (2006):

1. A ideia principal deve estar no enunciado;

2. Simplicidade no enunciado;

3. Evitar expressões rebuscadas;

4. Evitar informações irrelevantes;

5. Evitar dar dicas sobre a solução;

6. Evitar questionários sobre opiniões;

7. Não emendar um item no outro;

8. Minimizar o tempo de leitura;

9. Evitar erros gramaticais e ortográficos;

10. O número de perguntas deve ser proporcional à importância de cada tema;

11. Usar frases curtas e simples;

12. Evitar o uso de palavras negativas (não, nunca) e universais (todo, sempre, nada).

A validade do teste (este constituindo a hipótese), então, será estabelecida pela testagem empírica da verificação da hipótese (PASQUALI, 2003). Uma das formas de se estabelecer a validade de um instrumento é por meio da análise da consistência interna. Este tipo de análise permite avaliar a homogeneidade dos itens que compõem o teste, bem como se há correlação entre cada item e o resultado final do teste (OLIVEIRA e OLIVEIRA, 2007).

A análise fatorial é uma técnica estatística relativamente sofisticada, prática e muito usada, inclui a análise dos componentes principais e análise dos fatores comuns. É aplicado quando há um grande número de variáveis correlacionadas entre si, com o objetivo de identificar um número menor de novas variáveis alternativas, não correlacionadas e que, de algum modo, sumarizem as 
informações principais das variáveis originais encontrando os fatores ou variáveis latentes (MINGOTI, 2005).

A análise fatorial se realiza com o objetivo de determinar qual é o número de dimensões (fatores) que mede o teste, descobrir qual é o significado de cada um e obter uma pontuação de cada sujeito em cada dimensão (carga fatorial). Normalmente, o número de fatores que se mede em um teste é menor que o número de itens. Para descobrir o seu significado é necessário fixar uma das variáveis que saturam de forma elevada em cada dimensão. Quando o pesquisador enfrenta a tarefa de dar significado a um fator deve realizar um processo de encontrar nexo entre as variáveis. Além disso, os diferentes fatores extraídos não tem a mesma importância. Cada um explica uma determinada quantidade da variância total dos itens, que se expressa percentualmente e indica a importância das dimensões dos itens (ABAD et al, 2006).

A última etapa é a fidedignidade ou a precisão de um teste diz respeito às características que ele deve possuir, a saber, a de medir sem erros. Medir sem erros significa que o mesmo teste, medindo os mesmos sujeitos em ocasiões diferentes, ou testes equivalentes produzem resultados idênticos, isto é, a correlação entre estas duas medidas deve ser 1. Entretanto, como o erro está sempre presente em qualquer medida, esta correlação se afasta do 1 quando maior for o erro cometido na medida. A análise de precisão de um instrumento psicológico quer mostrar precisamente o quanto ele se afasta do ideal da correlação 1, de um determinado coeficiente que, quanto mais próximo de 1, menos erro o teste comete ao ser utilizado (PASQUALI, 2003).

Para Bispo e Gibertoni (2007) três aspectos fundamentais devem ser considerados na fidedignidade de mensurações qualitativas: precisão - repetir várias vezes a mesma mensuração no mesmo objeto e coletar praticamente o mesmo erro em todas elas, estabilidade - repetir várias vezes a mesma mensuração no mesmo objeto e obter resultados praticamente idênticos, consistência interna ou homogeneidade - indica que todos os itens da investigação qualitativa mensuram o mesmo aspecto do objeto previsto daquela investigação.

Há uma série de técnicas de estimativa de coeficientes de precisão que resultam da análise estatística dos dados de uma única aplicação de um teste a uma amostra representativa de sujeitos. Eles visam verificar a consistência interna do teste através da sua análise (PASQUALI, 2003). Assim, surgiram vários métodos para estimar os aspectos da fidedignidade como teste-reteste, bipartição, Kuder-Richardson e alfa de Cronbach também conhecido como coeficiente alfa.

Se a validade e a fidedignidade de uma mensuração qualitativa não são conhecidas, podem surgir dúvidas acerca dos resultados e conclusões obtidas por trabalhos que tenham como suporte esse tipo de mensuração, podendo comprometer decisões importantes. Por isso, é essencial conhecer as duas técnicas juntas, validade e fidedignidade, possibilitando dar maior credibilidade às mensurações qualitativas. A fidegnidade é um complemento da validade (BISPO e GIBERTONI, 
2007). Neste estudo, a fidedignidade foi medida através do alfa de Cronbach e a validade através da análise fatorial com rotação varimax.

\section{Metodologia}

O trabalho foi dividido em duas partes: inicialmente foi realizado um levantamento sobre as condições do transporte público do município. As informações pesquisadas foram:

- Informações gerais: Nome(s) da(s) empresa(s) operante(s); histórico da empresa; número de passageiros por mês; valor atual da passagem;

- Acessibilidade: Tipo de bilhetagem; tipo do traçado das linhas; total de linhas; número de terminais e descrição sucinta dos mesmos;

- Frequência: Frequência das linhas; forma de divulgação da frequência;

- Tempo de viagem: Tempo médio de viagem;

- Características dos pontos de paradas: Tamanho, presença de bancos, presença de lixeira, cobertura, e número de abrigos.

- Características dos veículos: número de veículos; assentos para deficientes, gestantes e idosos; idade média dos veículos.

- Sistema de informação: 1) Informações nos pontos de paradas, frequência, itinerário, nome da linha. 2) Informação no terminal, presença de mapa, presença de Itinerário, presença de postos de informações. 3) informações nos ônibus: presença de informações na lateral e na frente do ônibus,presença de letreiro eletrônico.

- Segurança: Número de acidentes com ônibus (caso tenha).

- Comportamento dos operadores: Número de funcionários, realização de treinamento, tipo de treinamento.

- Peculiaridades: Certificação de qualidade (como ISO e outras) e ações de marketing.

- A segunda parte foi à análise psicométrica da opinião dos usuários de transporte público. A psicometria foi utilizada na montagem do questionário e na análise dos dados. As etapas da segunda parte da pesquisa foram: escolha dos atributos, instrumento de medida, coleta de dados, tratamento estatístico e psicométrico.

\subsection{Escolha dos atributos}

Primeiramente para a escolha dos atributos foi realizada uma pesquisa em referências nacionais e internacionais para saber quais são os atributos mais utilizadas na mensuração da satisfação dos usuários de transporte coletivo por ônibus. Os autores brasileiros que trabalham com essa temática são: Farias (1985), Lima Junior (1994), Ferraz e Torres (2001), Santos (2008) e Rodrigues e Sorratini (2008). O conceito dos atributos foram descritos na Tabela 01, conforme 
definição de Ferraz e Torres (2001). A tabela sintetiza a visão brasileira sobre os atributos que são importantes em uma avaliação da qualidade do transporte público por ônibus sob o ponto de vista do usuário.

Tabela 01- Atributos da qualidade de transporte público

\begin{tabular}{cc}
\hline Fator & Conceito \\
Acessibilidade & $\begin{array}{c}\text { É à distância percorrida para iniciar e finalizar a viagem por } \\
\text { transporte público e a comodidade experimentada nesses percursos. } \\
\text { Está relacionada à transbordalidade do transporte. }\end{array}$ \\
\hline Tempo de viagem & $\begin{array}{c}\text { É o tempo gasto no interior dos veículos e depende da velocidade } \\
\text { média e da distância percorrida. }\end{array}$ \\
\hline Lotação & Quantidade de passageiros no interior dos coletivos. \\
\hline Confiabilidade & $\begin{array}{c}\text { É o grau de certeza dos usuários de que o veículo irá passar na } \\
\text { origem e chegar ao destino. }\end{array}$ \\
\hline Segurança & $\begin{array}{c}\text { Está focada na frequência de acidentes envolvendo veículos } \\
\text { coletivos. }\end{array}$ \\
\hline Características dos veículos & $\begin{array}{c}\text { A tecnologia e o estado de conservação dos veículos são fatores } \\
\text { determinantes na comodidade dos usuários. }\end{array}$ \\
\hline Características dos locais de paradas & Sinalização adequada e existência de cobertura e bancos para sentar. \\
\hline Sistema de informação & $\begin{array}{c}\text { Envolvem horários, itinerários, informações sobre a linha, } \\
\text { informações no interior dos veículos e nos terminais. }\end{array}$ \\
\hline Comportamento dos operadores & $\begin{array}{c}\text { Os aspectos importantes são: conduzir o veículo com habilidade, } \\
\text { tratar os passageiros com respeito. }\end{array}$ \\
\hline Pontualidade & $\begin{array}{c}\text { É a qualidade do cumprimento de horários estabelecidos pela } \\
\text { empresa. }\end{array}$ \\
\hline
\end{tabular}

Fonte: Ferraz e Torres (2001). Adaptado pelo autor

Os estudos internacionais sobre avaliação de transporte público sob o ponto de vista do usuário são próximos aos desenvolvidos no Brasil. O PORTAL (2003) - Promotion Of Results in Transport Research and Learning - utiliza os mesmos atributos para mensurar a qualidade, o que diferencia é que na Europa o atributo "meio ambiente", no sentido ecológico, também é avaliado e tem um peso na percepção dos usuários.

O trabalho de González, Pesqueira e Fernández (2000) foi fundamental para o desenvolvimento desta pesquisa. Eles utilizaram medidas psicométricas para avaliar o sistema de transporte urbano por ônibus sob a ótica do usuário na Espanha. O estudo foi desenvolvido em duas partes, sendo na primeira aplicado na cidade de Santiago da Compostela, com uma amostra relativa. Realizando as seguintes etapas: análise de itens, consistência interna, estrutura fatorial e validez. Com base no estudo anterior, o questionário foi aplicado em uma amostra maior na população de Gallega.

Para o desenvolvimento deste trabalho foram utilizados os seguintes atributos: acessibilidade, tempo de viagem, características dos veículos, comportamentos dos funcionários, segurança, sistema de informação, confiabilidade, características das paradas de ônibus, lotação, satisfação geral com o serviço de ônibus e nos horários de pico. Os atributos de satisfação geral e nos horários de pico foram incluso como sugestão de González et al (2000). 


\subsection{Instrumento de medida}

O instrumento de medida para realização desta pesquisa foi um questionário composto por 19 itens que avaliaram os atributos já citados, também foram coletados dados sobre sexo e renda. O questionário utilizado está na Figura 01. Este questionário foi validado psicometricamente por Gonzalez et al (2000) na Espanha. Para ser utilizado na realidade brasileira o instrumento foi traduzido e após um pré-teste sofreu pequenas alterações. Segundo Matar (1997) esse pré-teste é importante para o aprimoramento de um instrumento de coleta de dados, nenhuma pesquisa deveria iniciar sem que o instrumento utilizado tivesse sido convenientemente testado. A escala escolhida foi Likert por ser a escala mais utilizada em pesquisa de opinião. Foi dividida em foi de cinco ordens: discordo totalmente (01); discordo parcialmente (02); indiferente (0); concordo parcialmente (3); concordo totalmente (4).

O instrumento avalia os atributos da seguinte forma: acessibilidade (variável observável 1, 13 e 2), características dos veículos (variável observável 9,10 e 11), comportamentos dos funcionários (variável observável 18 e 19), segurança (variável observável 14 e 15), confiabilidade (variável observável 5),características das paradas de ônibus (variável observável 12 e 13), tempo de viagem (variável observável 3), lotação (variável observável 7), sistema de informação (variável observável 16 e 17), pontualidade (variável observável 4), satisfação geral e nos horários de pico (variável observável 8 e 6).

Figura 01 - Questionário utilizado na pesquisa

\begin{tabular}{|c|c|c|c|c|c|c|}
\hline 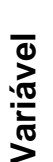 & $\begin{array}{l}\text { PESQUISA SOBRE A QUALIDADE NO TRANSPORTE } \\
\text { PÚBLICO } \\
\text { Marque com um x na opção escolhida }\end{array}$ & 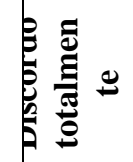 & 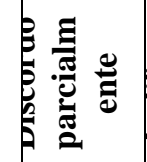 & 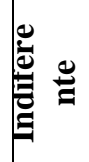 & ○ & 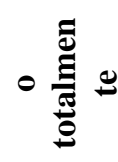 \\
\hline 1 & Os pontos de ônibus ficam próximos a sua casa/trabalho & & & & & \\
\hline 2 & É fácil o acesso a diversos bairros & & & & & \\
\hline 3 & É rápido o deslocamento do bairro até o centro & & & & & \\
\hline 4 & Os ônibus são pontuais & & & & & \\
\hline 5 & Quando tenho pressa utilizo o ônibus & & & & & \\
\hline 6 & Estou satisfeito com o serviço de ônibus do horário de pico & & & & & \\
\hline 7 & Os ônibus são lotados & & & & & \\
\hline 8 & Estou satisfeito com o serviço de ônibus na cidade & & & & & \\
\hline 9 & Andar de ônibus é confortável & & & & & \\
\hline 10 & Os ônibus estão limpos & & & & & \\
\hline 11 & Os ônibus estão em bom estado de conservação & & & & & \\
\hline 12 & Os pontos de ônibus são agradáveis de ficar & & & & & \\
\hline 13 & O número de paradas de ônibus é suficiente & & & & & \\
\hline 14 & Acho seguro andar de ônibus em relação a acidentes & & & & & \\
\hline 15 & Sinto-me seguro em relação à ocorrência de assaltos & & & & & \\
\hline 16 & Estou satisfeito com as informações nos pontos de ônibus & & & & & \\
\hline 17 & As informações no terminal são suficientes (mapa, horário) & & & & & \\
\hline 18 & Os motoristas e cobradores são educados & & & & & \\
\hline 19 & O motorista costuma frear e acelerar suavemente & & & & & \\
\hline
\end{tabular}

Fonte: Antunes (2009) 


\subsection{Coleta de dados}

Existem diferentes técnicas de coleta de dados, mas para esta pesquisa utilizou-se a técnica de abordagem que são conduzidas fora da residência dos indivíduos, por exemplo, em lugares públicos. Na coleta de dados às pessoas eram abordadas nos terminais centrais ou em bairros, pontos de parada ou dentro dos ônibus. Após a abordagem se expunha o objetivo da pesquisa e era entregue o questionário com uma caneta e papelão, servindo de apoio para o preenchimento, e em seguida explicava aos usuários a forma de preenchimento do instrumento de medida.

A amostra foi selecionada aleatoriamente a partir das variáveis: sexo, idade e renda. A coleta de dados foi realizada em linhas aleatórias e em horários diversos. Os dias e horários selecionados foram de segunda a domingo, das $7 \mathrm{~h} 30$ às $19 \mathrm{~h}$, a fim de incorporar na amostragem diferentes tipos de usuários. Considerou-se usuários, pessoas acima de 14 anos, que utilizam o transporte, pelo menos, duas vezes na semana. A pesquisa foi realizada em março de 2009 na cidade de Maringá-PR.

\subsection{Tratamento estatístico e psicométrico}

Os questionários que estavam respondidos de forma errada ou incompleta foram excluídos da amostragem, os que estavam parcialmente incompletos foram substituídos pela média. Os dados foram analisados através do software Statistica 7 onde criou-se um banco de dados com as respostas dos usuários do transporte público urbano. No primeiro momento avaliou-se as características socioeconômicas da população e no segundo momento procedeu-se a análise das atitudes dos usuários frente ao sistema. Para o tratamento estatístico, calculou-se a média ponderada conforme os vários graus de concordância/discordância. Foram atribuídos números para indicar a direção da atitude do respondente. As respostas: indiferente, discordo totalmente, discordo parcialmente, concordo parcialmente, concordo totalmente, foram atribuídos valores 0,1,2,3 e 4, respectivamente, para as assertivas favoráveis (positivas). Os valores foram invertidos quando a assertiva era desfavorável (negativa). A equação utilizada para realização da média ponderada está na Equação 01 .

$$
\mathrm{Mi}=\frac{\mathrm{x} 1 \mathrm{p} 1+\mathrm{x} 2 \mathrm{p} 2+\ldots \mathrm{xnpn}}{\mathrm{p} 1+\mathrm{p} 2 \ldots . \mathrm{pn}}
$$

Sendo:

P1 - peso valor 1;

P2 - peso valor 2;

Pn - peso valor $n$;

X1 - número de respostas da escala 1;

X2 - número de respostas da escala 2; 
Xn - número de respostas da escala n;

$\mathrm{Mi}$ - média ponderada do atributo i.

Após o cálculo da média ponderada classificou-se o nível de satisfação dos usuários (Tabela 02).

Tabela 02 - Níveis de satisfação

\begin{tabular}{c|c}
\hline Média ponderada & Nível de satisfação \\
\hline 1 a 1,99 & Insatisfação \\
2 a 2,99 & Satisfação média \\
3 a 4 & Satisfação plena \\
\hline
\end{tabular}

O tratamento psicométrico teve como objetivo calcular a fidedignidade e validade do teste. Para calcular a fidedignidade dessa pesquisa utilizou-se o alfa de Cronbach, calculado segundo a Equação 02. Cronbach foi quem propôs um coeficiente geral que reflete o grau de covariância dos itens entre si, servindo, assim, de indicador da consistência interna do próprio teste Pasquali (2003).

$$
r=\frac{C x, y}{S x S y}
$$

Sendo:

$r$ - Coeficiente de Cronbach;

Cxy - Covariância ou variância conjunta das variáveis X e Y;

Sx - desvio padrão da variável X;

Sy - desvio padrão da variável Y.

A validação deste instrumento foi realizada através da análise fatorial com o método de extração dos componentes principais com rotação varimax. Quanto à aplicação dessa técnica na amostra de tamanho $\mathrm{n},[\mathrm{x} 1, \mathrm{x} 2, \ldots, \mathrm{xn}]$, é preferível se trabalhar com a matriz de correlação amostral R, uma vez que dessa forma se eliminam efeitos de escala das variáveis. Outro conceito muito importante é o do escore fatorial. Trata-se do valor supostamente assumido pelo fator $\mathrm{Fj} \mathrm{j}=1,2, \ldots, \mathrm{m}$ para uma observação individual x. É importante mencionar também que no caso de se desejar obter uma estrutura de fácil interpretação para os pesos, tal que cada variável tenha peso alto em um único fator e pesos baixos ou moderados nos demais fatores, é necessário fazer uma rotação rígida dos fatores (CARDOSO, 2004).

A rotação varimax foi escolhida, pois é importante obter fatores com a maior ortogonalidade possível, uma vez que o objetivo principal é medir componentes do construto satisfação com transporte público urbano com relativa independência entre si, neste método os eixos dos fatores são rotados para uma posição na qual a soma da variação das cargas fatoriais é a máxima possível. Além disso, esse tipo de rotação minimiza o número de fatores em cada variável. 


\section{Resultados}

\subsection{Levantamento preliminar}

Desde 1978, a empresa Transporte Coletivo Cidade Canção detêm o monopólio na execução dos serviços de transporte urbano em Maringá. O número de usuários no momento em que foi aplicada a pesquisa era em torno de 2.117.430 usuários/mês, incluindo estudantes, idosos e deficientes. A passagem custava $\mathrm{R} \$ 2,20$ em março de 2009. O número de motoristas era de aproximadamente 690 funcionários. A frota era composta por 225 veículos, sendo 195 do tipo padron, 21 microônibus e 9 ônibus articulados (MERCADO, 2008) e a idade média dos ônibus em torno de 3 a 5 anos.

Em Maringá existem oficialmente 53 linhas urbanas, onde a maioria das linhas que realizam o transporte de passageiros no município é do tipo radial, essas linhas ligam diretamente o centro da cidade aos bairros, ou o centro a pontos atrativos de fluxos populacionais como Estádio de Futebol, Shopping Centers, Hospitais, Universidades etc. Além da linha interbairros, que percorre o trajeto de forma circular, o sistema de transporte coletivo de Maringá, até o momento da pesquisa, não tinha nenhuma outra linha que faça a interligação de bairros sem passar pelo centro da cidade (PRADO e PASSINI, 2003).

A integração é feita por meio de um cartão. Cada linha tem um tempo para integração, possibilitando que os usuários possam fazer conexão de duas linhas, pagando apenas uma tarifa. Em determinados horários, o usuário que usar o cartão no sistema de transporte da cidade, ganha um crédito de 1/10 do valor da passagem. Ou seja, a cada dez viagens, o usuário ganha uma.

A frequiência das linhas pode ser visualizada no site www.tccc.com.br. No terminal central nos pontos de embarque existem placas informando a freqüência das linhas. Para medir o tempo médio de viagem das linhas foram escolhidas linhas aleatórias e marcou-se o tempo gasto do ônibus para completar o trajeto. O resultado obtido indica que o menor tempo foi de 20 minutos e o maior foi de $1 \mathrm{~h} 15 \mathrm{~min}$.

Conforme a SETRAN - Secretaria de Trânsito de Maringá existem 2.428 pontos de paradas de ônibus, sendo que 1.065 não têm cobertura. Os pontos, pelo menos da área central em Maringá, oferecem bancos, lixeiras e cobertura. O tamanho varia de acordo com o número de usuários, quanto maior a atração de pessoas na área, maiores em termos de comprimento são os pontos de ônibus. Alguns pontos são utilizados como ferramenta de marketing através de convênios com a Prefeitura Municipal de Maringá.

Nos pontos de embarque do terminal central pode ser observado os itinerários das linhas e freqüência de atendimento nos dias da semana, sábados e domingos e/ou feriados. Em relação ao 
sistema de informação nos pontos de paradas não existem informações como freqüência, itinerário ou nome da linha.

\subsection{Perfil da amostra}

Em relação à amostragem coletada participaram 383 usuários, conforme sugestão de Antunes (2009), onde se considerou um erro amostral de 5\% e a margem de confiança de 95\%. A amostra era composta por $65 \%$ eram mulheres e $35 \%$ eram homens, com idades compreendidas entre 14 a 62 anos, procedentes de diferentes zonas da cidade. Em relação à renda salarial, 26\% responderam que recebiam até $\mathrm{R} \$ 450,00$ por mês; $45 \%$ responderam que tem uma renda entre $\mathrm{R} \$$ 450,00 a $\mathrm{R} \$ 900,00 ; 25 \%$ afirmaram que recebem entre $\mathrm{R} \$ 900,00$ a $\mathrm{R} \$ 1.200,00$ e apenas $14 \%$ recebem acima de $\mathrm{R} \$ 1.200,00$ (Gráfico 01). Observa-se que o salário mínimo era $\mathrm{R} \$ 450,00$ - na época.

Gráfico 01 - Perfil econômico da amostra

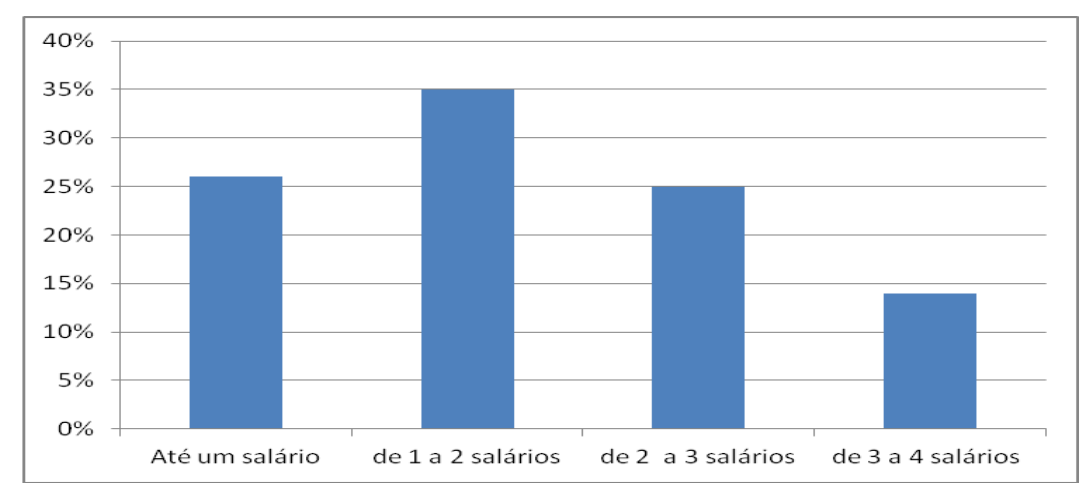

Fonte: do autor

\subsection{Nível de satisfação e análise psicométrica}

A Tabela 03 nos mostra o nível de satisfação/insatisfação conforme cada item do questionário. A variável 01 mostra que o usuário está satisfeito plenamente e as variáveis 02 e 13 mostram que o usuário está satisfeito em relação à acessibilidade ao transporte público, isso quer dizer que quanto menos o passageiro caminhar, melhor é a acessibilidade do sistema de transporte público (SANTOS, 2008). Este dado indica que a distribuição dos pontos de ônibus pela cidade é satisfatória. Os 2.428 pontos de paradas cobrem toda a área urbana do município e é o atributo que teve a maior nota em relação aos demais. Este atributo é importante porque a falta de acessibilidade pode gerar aflição e insegurança nos usuários de transporte coletivo. O autor Gonçalves (2000) menciona que em muitas cidades as pessoas não encontram serviço de transporte ligando diretamente origens e destinos, desta forma, o usuário deve descobrir sozinho o caminho correto gerando desconforto e incerteza e nem todas as cidades possuem um sistema integrado de transporte para facilitar a transferência. De forma complementar, a variável 13 (número de paradas) confirma 
a variável 01 sobre acessibilidade ao sistema. $\mathrm{O}$ usuário tem a percepção que o número de paradas de ônibus são suficientes e satisfatórias para o uso no cotidiano.

Os atributos que apresentam grau de satisfação média são:

1) sistema de informação do transporte público (variável 16 e 17): os usuários estão satisfeitos com as informações nos terminais e nos pontos de ônibus, ou seja, as informações presentes são suficientes. É um atributo importante para demonstrar organização do serviço prestado.

2) estado de conservação dos ônibus (variável 10 e 11): a idade dos ônibus é entre 3 a 5 anos, ou seja, os ônibus são relativamente novos e segundo a percepção dos usuários estão em bom estado de conservação. É importante frisar que bom estado de conversação inclui não apenas a aparência física dos veículos, mas também a limpeza, ruídos e número de portas. A existência de porta de desembarque central e corredores largos facilitam a locomoção, principalmente, em horários de pico. Pode-se dizer que a aparência do veículo (aspecto visual da parte externa e interna) influi no grau de satisfação dos usuários, pois a estética (sensação de beleza) está sempre presente na natureza humana (FERRAZ e TORRES, 2001). A variável 10 indica que a limpeza dos veículos é realizada de forma satisfatória também, embora a variável 09 indica que os usuários reconhecem que os ônibus não são confortáveis.

3) segurança (variável 14 e 15): os usuários sentem-se seguros quando andam de ônibus em relação à acidentes, isso, indica que os motoristas conduzem os veículos de forma cuidadosa. $\mathrm{O}$ resultado indica que a empresa operadora tem bom resultado em relação ao treinamento de direção defensiva dos motoristas e mostra preocupação da empresa em relação à segurança das pessoas durante o seu transporte. É um dado importante porque influencia diretamente na percepção dos usuários sobre a qualidade de prestação dos seus serviços e é um aspecto facilmente percebível pelos usuários.

4) comportamento dos funcionários (variável 18 e 19): a percepção geral dos usuários é de que os funcionários são educados e os motoristas dirigem suavemente, de uma forma geral. Esta variável confirma o resultado das variáveis citadas anteriormente. Também é um atributo que indica uma boa imagem da empresa.

5) pontualidade (variável 04): os ônibus são pontuais e é um atributo importante porque influencia na escolha do modal realizada pelos usuários. A pontualidade é fundamental para criar laços de confiança entre os usuários e a empresa; entre os usuários e o sistema de transporte público.

6) tempo de viagem (variável 03): este é um dos atributos mais importantes para os usuários de transporte coletivo, também é um dos mais difíceis de serem mantidos porque a medida em que se reduz o tempo de viagem, o usuário fica cada vez mais exigente desejando cada vez mais que o 
deslocamento seja realizado em menor tempo possível. O estudo de Portilha et al (2008) e Dell'Olio, Ibeas e Cecin (2011) indica que os atributos mais valorizados pelos usuários são o tempo de espera e o tempo de viagem. Nos tempos atuais o ser humano querer ter o máximo de eficiência, gastando o menor tempo possível das suas atividades, porém, realizando-a com qualidade. Essa tendência comportamental é mundial. Decorrente a isso, ninguém quer perder tempo, principalmente no transporte, a população considera tempo perdido, o que equivalente à improdutividade. Para isso, é importante ter ações que minimizem essa aflição, distraindo o usuário para não se afligir com esse "tempo perdido", por exemplo, em Brasília o gestor local distribui livros nos pontos de paradas onde os usuários podem levar e ler durante o percurso da viagem entregando em outro ponto. De uma forma geral, o usuário está satisfeito com o tempo de viagem que leva para percorrer todo o trajeto, mais é importante frisar que as linhas que tem o deslocamento mais demorado são alvos de insatisfação. O mapeamento dessas linhas não foi alvo de estudo.

7) De uma forma geral, a satisfação com o sistema de transporte público é positiva, com exceção de horários de pico (variável 08). A título de comparação, os estudos internacionais indicam em ordem decrescente de maior importância as características que interferem na qualidade por ônibus: frequência, tempo de viagem, comportamento do motorista, lotação, conforto (ventilação), segurança, educação dos operadores (Dell'Olio, Ibeas e Cecin, 2011). O nosso estudo de caso demonstra que das sete variáveis a empresa alcançou quatro aspectos de forma satisfatória. A frequência, embora não tenha sido alvo da pesquisa, sob o ponto de vista por usuários, ela varia conforme a linha que está sendo utilizada. De uma forma geral, os ônibus passam de 15 a 20 minutos em dias de semana. Coforme Santos (2008) a frequência tem relativa importância para os usuários que conhecem previamente os horários, pois lhe confere maior ou menor flexibilidade na utilização do sistema.

Em relação às variáveis que apresentam graus de insatisfação, o resultado indica que confiança no sistema de transporte, satisfação dos horários de pico, lotação, conforto nos ônibus e nos pontos de parada são aspectos do sistema de transporte público que precisam ser melhorados.

8) confiabilidade (variável 05): esta variável indica que o usuário não confia plenamente no transporte, embora, seja pontual. Observa-se que a empresa ainda não conquistou um grau de confiança satisfatório dos seus usuários. Os usuários responderam que quando tem horário marcado para chegar ao destino desejado, os usuários optam por não utilizar o transporte público pelo fato de não confiarem plenamente no sistema de transporte público, ou utilizam o transporte público saindo mais cedo de sua casa o que também causa certo desconforto pela percepção de tempo perdido. Esse dado pode indicar a fuga de clientes para outros meios de locomoção, como: moto táxi, táxi, carro, vans ou até mesmo optam pelo deslocamento a pé por considerarem mais rápido em situações 
que exigem agilidade. É um dado que merece atenção dos responsáveis técnicos. Outro fator relevante é que a confiabilidade não depende apenas da empresa operante, o sistema de transporte está sujeito a fatores externos como condição de via, tráfego, acidentes provocados por terceiros que influenciam diretamente na percepção de confiabilidade do sistema de transporte público.

Ferraz (1990) comenta que diversos fatores podem ocasionar o não cumprimento dos horários de partida e chegada. O não cumprimento dos horários, ou não realização das viagens representam inconvenientes quanto menor for à frequência de atendimento. Em linhas de alta frequência, geralmente, o aspectos confiabilidade não é em geral afetado por pequenos atrasos ou adiantamentos.

9) O atributo lotação (variável 07) é determinada pela relação entre o número de passageiros no interior do veículo nos horários de pico, momento de lotação máxima, e sua capacidade. A lotação traz vários inconvenientes, viagens de grande duração realizada em pé são cansativas, o contato corpóreo com outras pessoas incomoda e as operações de embarque/desembarque ficam mais difíceis de serem executadas. Observa-se que é a menor nota atribuída na pesquisa. A lotação é o que causa maior desconforto nos usuários de transporte coletivo. $\mathrm{O}$ órgão gestor deve estar atento a essa reclamação buscando observar quais são as linhas lotadas, colocando mais ônibus a disposição.

Ferraz (1990) propõe um padrão de qualidade quanto à lotação dos veículos segundo a Tabela 06. Ele fez um estudo sobre o grau de lotação em ônibus e classificou segundo o nível de qualidade dos serviços. Quando menor a densidade de passageiros, melhor é a qualidade do serviço de transporte.

Tabela 06 - Padrão de qualidade quanto à lotação dos veículos

\begin{tabular}{cc}
\hline Nível de Serviço & Densidade (Passageiros/m2) \\
\hline A & Só sentados \\
B & 0 a 1,5 \\
C & 1,5 a 3,0 \\
D & 3,0 a 4,5 \\
E & 4,5 a 6,0 \\
F & $>6,0$ \\
\hline
\end{tabular}

Fonte: Ferraz (1990)

10) a variável 09 está relacionada ao atributo característica dos veículos que foi discutido acima. É interessante frisar que à medida que aumenta a idade dos usuários, os atributos limpeza e comodidade tem peso maior (Portilha et al, 2008). Os ônibus devem ser projetados para transportar passageiros com segurança e conforto. A avaliação das condições ergonômicas, associada à pesquisa de opinião dos usuários é de fundamental importância para tradução das necessidades dos usuários em serviços. Diversas características dos ônibus podem influenciar diretamente na qualidade de conforto dos mesmos: o assento, a higiene e segurança, o espaço para circulação 
interna, as dimensões das portas, a roleta, os apoios, a altura dos degraus a visibilidade, e as condições ambientais, como conforto térmico, ruídos e iluminação (SANTOS, 2008).

11) A insatisfação em relação ao conforto nos pontos de ônibus (variável 12) está ligada às questões estruturais como falta de banco, falta de abrigo, falta de uma proteção adequada para os dias de chuva ou muito ensolarado, porque em relação à acessibilidade ao sistema o resultado indica satisfação plena. Tendo um abrigo de ônibus estimulante promovemos a qualidade de vida da população (GALLAGHER, 2006) e melhoramos a imagem do transporte público (ACTION, 2008). Os primeiros abrigos de ônibus eram essencialmente uma cobertura, hoje em dia as superfícies laterais são importantes fechando três das quatro paredes possíveis, para que o usuário tenha visibilidade, podendo ver o ônibus antes de chegar na parada e assim ter tempo de estender a mão para solicitar a sua parada. As características esperadas nos abrigos de ônibus são: custo baixo, fácil manutenção, material resistente, boa aparência, tamanho adequado, iluminação suficiente, distância entre os pontos adequada, localização adequada, informações sobre as linhas e horários. Os abrigos não podem obstruir a passagem dos pedestres e devem oferecer acessibilidade aos usuários (NEOTERIC, 2008). No planejamento desses abrigos devem-se observar as características citadas e as características ambientais como topografia, vegetação e clima (SUTHERLAND, 2008), por exemplo, em Dubai os pontos de ônibus tem ar-condicionado, sendo adaptados ao clima local. Para a realidade brasileira de cidades médias o trabalho de Antunes \& Graebin (2008) oferece uma metodologia para avaliar os pontos de ônibus no Brasil.

A manutenção e limpeza dos pontos são fatores importantes pois precisam ser realizados periodicamente. Para que esses custos sejam cobertos sugere-se parcerias entre empresas privadas e o responsável pela manutenção para que as laterais dos abrigos sejam usados como ferramentas de marketing.

12) O resultado da insatisfação dos horários de pico (variável 06) já era previsto devido o acúmulo de outros fatores que indicam insatisfação, como: lotação, falta de conforto e falta de confiança no sistema. Isso também resulta em fuga de usuários para concorrentes. O resultado indica perda da clientela e é importante destacar que os aspectos poderiam ser melhorados no sistema a fim de aumentar a satisfação dos usuários., atitudes como melhorias estruturais e sonora nos ônibus, melhoria da circulação, melhoria estrutural nos pontos de paradas são ações que poderiam mudar a opinião dos usuários, embora seja compreensível que essas medidas não dependem apenas da empresa responsável pelo transporte. 


\begin{tabular}{|c|c|c|}
\hline Variável Observável & $\begin{array}{l}\text { Média } \\
\text { Ponderada }\end{array}$ & Nível de satisfação \\
\hline Os pontos de ônibus ficam próximos a sua casa/trabalho & 3,14 & Satisfação plena \\
\hline É fácil o acesso a diversos bairros & 2,43 & Satisfação média \\
\hline É rápido o deslocamento do bairro até o centro & 2,37 & Satisfação média \\
\hline Os ônibus são pontuais & 2,29 & Satisfação média \\
\hline Quando tenho pressa utilizo o ônibus & 1,94 & Insatisfação \\
\hline Estou satisfeito com o serviço de ônibus do horário de pico & 1,86 & Insatisfação \\
\hline Os ônibus são lotados & 1,74 & Insatisfação \\
\hline Estou satisfeito com o serviço de ônibus na cidade & 2,25 & Satisfação média \\
\hline Andar de ônibus é confortável & 1,83 & Insatisfação \\
\hline Os ônibus estão limpos & 2,32 & Satisfação média \\
\hline Os ônibus estão em bom estado de conservação & 2,54 & Satisfação média \\
\hline Os pontos de ônibus são agradáveis de ficar & 1,73 & Insatisfação \\
\hline O número de paradas de ônibus é suficiente & 2,46 & Satisfação média \\
\hline Acho seguro andar de ônibus em relação a acidentes & 2,53 & Satisfação média \\
\hline Sinto-me seguro em relação a assaltos & 2 & Satisfação média \\
\hline Estou satisfeito com as informações nos pontos de ônibus & 2,01 & Satisfação média \\
\hline As informações no terminal são suficientes & 2,62 & Satisfação média \\
\hline Os motoristas e cobradores são educados & 2,34 & Satisfação média \\
\hline O motorista costuma frear e acelerar suavemente & 2,08 & Satisfação média \\
\hline
\end{tabular}

A análise psicométrica foi dividida em duas partes: fidedignidade e confiabilidade. A fidedignidade está relacionada com a confiabilidade do instrumento - relacionada com a repetição do teste num mesmo sujeito obtendo o mesmo resultado. Um teste fidedigno tem um resultado mais ou menos estável. Os atributos utilizados desta pesquisa foram testados através do cálculo do coeficiente Alfa de Cronbach, que mede a consistência interna do teste, o resultado do alfa foi de 0,86. Conforme Evrad (1993) são aceitáveis valores de alfa entre 0,60 e 0,80 para estudos exploratórios. No caso de estudos confirmatórios são recomendados alfas superiores à 0,80 . Neste sentido, considera-se o instrumento utilizado como sendo confiável.

A análise de confiabilidade foi realizada através da análise fatorial. A análise fatorial realizada pelo método componentes principais e rotação varimax indicou uma estrutura de oito fatores. Adotando o critério estabelecido por Pasquali (2003), escolheu-se o item que apresentava uma carga fatorial maior de 0,50 o qual representa bem um fator comportamental e indica grau de correlação significante entre a variável e o fator considerável.

A análise fatorial demonstrou que os fatores que melhor explicam a satisfação dos usuários se referem à suficiência do serviço e cumprimento de horários, estado dos ônibus e informação aos usuários e paradas de ônibus. 
O primeiro fator batizado de segurança, mede os itens 14 e 15 que se refere, respectivamente a segurança em relação a acidentes e assaltos. O fator 2 foi denominado de acessibilidade, relaciona-se aos itens 1 (proximidade dos pontos de paradas) e 2 (facilidade a diversos bairros).

Tabela 05 - Autovalores e variância

\begin{tabular}{ccccc}
\hline Fator & Autovalores & \% total variância & Autovalores acumulado & \% variância acumulada \\
\hline 1 & 5,77 & 30,39 & 5,77 & 30,39 \\
\hline 2 & 1,38 & 7,27 & 7,15 & 37,66 \\
\hline 3 & 1,17 & 6,18 & 8,33 & 43,85 \\
\hline 4 & 1,03 & 5,43 & 9,36 & 49,28 \\
\hline 5 & 1,00 & 5,30 & 10,37 & 54,59 \\
\hline 6 & 0,94 & 4,98 & 11,32 & 59,58 \\
\hline 7 & 0.90 & 4,78 & 12,22 & 64,36 \\
\hline 8 & 0,83 & 4,40 & 13,06 & 68,77 \\
\hline
\end{tabular}

O terceiro denominado de operacional agrupa os itens 16 (informações nos pontos de ônibus), 17 (informações no terminal), 18 (comportamento dos operadores) e 19 (condução do ônibus pelo motorista). O quarto fator chamado de características dos ônibus avalia os itens 10 (limpeza dos ônibus) e 11 (estado de conservação dos ônibus). O quinto fator refere-se à lotação dos ônibus, item 7. O sexto fator relaciona-se ao sexto atributo, a confiabilidade no sistema de ônibus. O sétimo fator denominado de tempo relaciona-se ao item 3 (tempo de deslocamento), 4 (pontualidade) e 6 (serviço no horário de pico). O oitavo fator é chamado de conforto avalia os itens 8 (satisfação geral), 9 (conforto nos ônibus), 12 (conforto no pontos de ônibus). A Tabela 04 oferece uma matriz fatorial com o valor de suas cargas fatoriais de cada variável observável.

Tabela 04 - Análise fatorial

\begin{tabular}{|c|c|c|c|c|c|c|c|c|}
\hline \multirow{2}{*}{ Variáveis } & \multicolumn{8}{|c|}{ Fatores } \\
\hline & F1 & F2 & F3 & F4 & F5 & F6 & F7 & F8 \\
\hline Os pontos de ônibus ficam próximos a sua casa/trabalho & & 0,83 & & & & & & \\
\hline É fácil o acesso a diversos bairros & & 0,75 & & & & & & \\
\hline É rápido o deslocamento do bairro até o centro & & & & & & & 0,63 & \\
\hline Os ônibus são pontuais & & & & & & & 0,66 & \\
\hline Quando tenho pressa utilizo o ônibus & & & & & & 0,87 & & \\
\hline Estou satisfeito com o serviço de ônibus do horário de pico & & & & & & & 0,62 & \\
\hline Os ônibus são lotados & & & & & 0,89 & & & \\
\hline Estou satisfeito com o serviço de ônibus na cidade & & & & & & & & 0,55 \\
\hline Andar de ônibus é confortável & & & & & & & & 0,80 \\
\hline Os ônibus estão limpos & & & & 0,81 & & & & \\
\hline Os ônibus estão em bom estado de conservação & & & & 0,78 & & & & \\
\hline Os pontos de ônibus são agradáveis de ficar & & & & & & & & 0,50 \\
\hline \multicolumn{9}{|l|}{ O número de paradas de ônibus é suficiente } \\
\hline Acho seguro andar de ônibus em relação a acidentes & 0,77 & & & & & & & \\
\hline Sinto-me seguro em relação à ocorrência de assaltos & 0,81 & & & & & & & \\
\hline Estou satisfeito com as informações nos pontos de ônibus & & & 0,50 & & & & & \\
\hline As informações no terminal são suficientes & & & 0,50 & & & & & \\
\hline Os motoristas e cobradores são educados & & & 0,80 & & & & & \\
\hline O motorista costuma frear e acelerar suavemente & & & 0,59 & & & & & \\
\hline
\end{tabular}


Através da análise de componentes principais foi observado que $68,77 \%$ do total da variância pode ser explicada por 8 fatores. Fazendo a análise dos autovalores maiores observa-se que 5 fatores explicam 54,59\% da variância total do questionário (Tabela 05). Observa-se que fator 01 corresponde a 30,39\% da variância total. O pesquisador espera que a análise fatorial desempenhe um papel confirmatório, ou seja, avalie o grau em que os dados satisfazem a estrutura esperada. Neste caso, a pesquisa está estruturada em oito fatores associado a satisfação da qualidade do transporte público de 19 variáveis e 12 atributos. Ou seja, o resultado final pode ser agrupado em 08 fatores que explicam $68,88 \%$ da variância acumulada.

\section{Considerações finais}

A pesquisa de opinião tem ganhado atenção dos empresários porque é importante para manter a imagem de empresa e cativar seus clientes. A psicometria é uma ferramenta útil para ser usada em situações onde o objeto de pesquisa é algo intrínseco e subjetivo. Neste caso, a satisfação do usuário depende da própria percepção que tem do sistema de transporte público e pode utilizá-la para mensurar matematicamente o nível de satisfação com confiabilidade e fidedignidade do resultado. A metodologia proposta pode ser utilizada em outros tipos de estudos que visam medir a satisfação da qualidade de outro objeto social.

Este estudo contribui para conhecer as atitudes e a avaliação da população frente ao sistema de transporte local e para contribuir na disseminação de uma gestão mais eficiente. É importante que os órgãos gestores do município percebam os benefícios que os resultados das pesquisas de opinião trarão para a gestão do transporte coletivo por ônibus, e possam acatar algumas sugestões deste trabalho para serem aplicadas na melhoria do sistema de transporte público do município. De uma forma geral, o atributo que gera maior satisfação no usuário é em relação à acessibilidade ao sistema de transporte público, e o que gera maior insatisfação é a lotação. Observa-se que não foi o foco do trabalho identificar em qual linha os usuários estão insatisfeitos devido à lotação. É importante como um estudo complementar e futuro fazer o levantamento das linhas de ônibus que apresentam mais problemas de lotação. Quanto ao fator lotação, é importante dispor de mais veículos principalmente nos horários de pico, possibilitando menores índices de lotação nos carros.

Em relação à análise psicométrica, os itens podem ser agrupados em oito fatores, os quais explicam $68,77 \%$ da variância. O questionário apresenta consistência interna aceitável, ou seja, ele realmente mede o que se pretende medir, isso torna a pesquisa fidedigna e confiável. O Alfa de Cronbach é uma importante ferramenta matemática para indicador a consistência interna do próprio teste, neste caso, o alfa demonstra que o resultado é confiável porque os itens estão relacionados e cada um contribui com uma informação inédita. 
É interessante que o órgão gestor acrescente em seus processos de licitação, instrumentos de monitoramento, isto é, critérios para avaliação do sistema de transporte público também sob o ponto de vista dos usuários. Como pesquisa futura deixa-se como sugestão a aplicação do questionário visando à estratificação do nível de satisfação por classe econômica e de gênero.

\begin{abstract}
This paper aims to evaluate the user satisfaction regarding the quality of urban public transport system. The evaluated attributes were: accessibility, travel time, capacity, timeliness, information system, vehicle characteristics, employee behaviors, safety, reliability, features of bus stops and general satisfaction and in rush times. In general, the attribute that leads to greater user satisfaction is about the accessibility to public transport system, and that generates the most dissatisfaction is related to crowded vehicles. As for the capacity factor, the operator should order more vehicles, particularly in rush hours, allowing lower rates of crowded vehicles. Regarding the psychometric analysis, the items can be grouped into eight factors, which explain $68.7 \%$ of the variance. The questionnaire has acceptable internal consistency, means that, it actually measures what it purports to measure, it makes searching trustworthy and reliable. We conclude that it is necessary to expand the appreciation of the survey, not only to value the technical data, but the different views: the users, policy makers and entrepreneurs, thus increasing the quality of service provided.
\end{abstract}

Key-words: public transport; service delivery; measurement.

\title{
Referências
}

ABAD, F.J.; G, J.; O, J.; P, P.; Introducción a la psicometria: teoria clássica de los tests y teoria de la respuesta al item. Facultad de Psicologia: UAM, 2006.

ACTION. Toolkit for Assessment of bus stop accessibility and safety (quick check-list). Disponível em: <www.projectatio.org>. Acesso em 30/05/08.

ANTUNES, E. M. ; GRAEBIN, T. Avaliação da Qualidade dos Abrigos de Ônibus no município de Campo Mourão. In: V ENDITEC Encontro Nacional de Difusão Tecnológica, 2008, Medianeira. V ENDITEC Encontro Nacional de Difusão Tecnológica, 2008.

ANTUNES, E. M.Avaliação do transporte público por ônibus sob o ponto de vista do usuário em cidades médias paranaenses.Dissertação (Mestrado). Universidade Estadual de Maringá: Maringá, 2009.

BISPO, C.A.F.; GIBERTONI, D. Coeficientes de fidedignidade para mensuração qualitativas. In Encontro Nacional de Engenharia de Produção, XXVII, Foz do Iguaçu. Anais...Foz do Iguaçu : ENEGEP, 2007.

CANCADO, V.L. Levantamento de opinião dos usuários em relação aos atributos dos transporte por ônibus. In Congresso de Pesquisa e Ensino em Transportes, IX, 1995. Anais... São Carlos: ANPET, .p. 1004-1014.

CARDOSO, F.A.R. Análise da qualidade no setor de serviço segundo o método de avaliação SERVQUAL. UFPR. Dissertação de Mestrado, 2004.

DELL'OLIO, L; IBEAS, A., CECIN, P. The quality of service desired by public transport use. Transport Policy. v. 18, n. 1, January 2011, Pages 217-227.

\section{cross ref}

EVRARD, Y. La satisfaction des consommateurs: état des recherché. Anais.. 17 ENANPAD. p. 59-68, 1993. 
FARIA, C.A. Percepção do usuário com relação às características do nível de serviço do transporte coletivo urbano por ônibus. Dissertação (Mestrado), Escola de Engenharia de São Carlos- EESC, São Carlos, 1985.

FERRAZ, A.C.P. e TORRES, I.G.E. Transporte público urbano. São Carlos: Rima, 2001.

FERRAZ, A.C.P. Sobre a eficiência e a eficácia do transporte público nas cidades médias. Tese (Livre docência). Escola de Engenharia de São Carlos- EESC, São Carlos, 1990.

GALLAGHER, J. Mayor Bloomberg unveils first new bus shelter as part of coordinated streer-furniture franchise. Disponível em: <www.nyc.gov/cgi-bin>. Acesso em: 30 maio 2008.

GONZÁLEZ, M.S.R.; PESQUEIRA, G.S.; FERNANDEZ,C.A. Construcción y análisis de um cestionario de evaluación de los medios de transporte público. Psicothema.. v. 12, n. 3, p. 399-405, 2000.

KAWAMOTO, E. Um novo enfoque do processo de escolha em transporte com tratamento baseado na psicofísica multidimensional. Tese (Doutorado). Escola de Engenharia de São Carlos, EESC, São Carlos, 1987.

LIMA JUNIOR, O.F. Qualidade em serviços de transportes. Manual técnico da qualidade Universidade de São Paulo: Ministério dos Transportes, 1994.

MARTINS, E.R.C.; ARAGAO, J.J.G.; MIAZAKI, E.S. Segmentação do mercado de transportes urbanos de passageiros: uma abordagem pela análise de agrupamentos. In Congresso de Pesquisa e Ensino em Transportes, XI, Rio de Janeiro. Anais... Rio de Janeiro: ANPET, 1997, p. 887-896.

MASSLER, J. A. V. Características dos serviços e escolha modal nos transportes. In Congresso de Pesquisa e Ensino em Transportes, VIII, São Paulo. Anais... Recife: ANPET, 1994, p. 71-72.

MATTAR, F.N. Pesquisa de marketing: metodologia, planejamento. Vol. 01, 4º ed, São Paulo, Editora Atlas, 1997.

MERCADO, R. G. Acessibilidade e mobilidade de cadeirantes no transporte público urbano de Maringá. Dissertação (Mestrado). Maringá: UEM, 2008.

MINGOTI, S.A. Análise de dados através de métodos de estatística multivariada: uma abordagem aplicada. Belo Horizonte: Editora UFMG, 2005.

NEOTERIC. Busshelters. Disponível em: <www.busshelters4u.co.uk/bus_shelter.html>. Acesso em 30/05/2008. Acesso em: 30 ago de 20008.

OLIVEIRA, J. G. R. A importância do sistema de transporte coletivo para o desenvolvimento do município de Campo Grande. Dissertação (mestrado). Universidade Católica Dom Bosco, Campo Grande, 2003.

PASQUALI, L. Psicometria: teoria dos testes na psicologia e na educação. Petrópolis, Rio de Janeiro: Vozes, 2003.

PORTAL. Benchmarking e gestão da qualidade nos transportes públicos. Disponível em: 〈www.eu-portal.net>. Acesso em 20 de jan 2013.

PORTAL. Benchmarking e gestão da qualidade nos transportes públicos. Disponível em: <www.eu-portal.net>. Acesso em 30 de jan . 2009.

PORTILHA, A.I.; OLIO, L.D.; ROJAS,F.G.;REVUELTA,M.J.G. Análisis de La calidad em el transporte público:el caso de Santander. Disponível em:<www.unican.es>. Acesso em: 02 de dez de 2008.

PRADO, J.P.B.; PASSINI, E.Y. O sistema de transporte coletivo urbano de Maringá : estudo da realidade e das possibilidades. Revista Acta Scientiarum: human and social sciencies, v. 25, p.165-173, 2003.

RIBEIRO NETO, A. A. A Contribuição a avaliação de transporte urbano por ônibus. Dissertação (Mestrado). Escola de Engenharia de São Carlos - EESC, São Carlos, 2001.

RODRIGUES, M.A; SORRATINI, J.A. A qualidade no transporte coletivo urbano. In Congresso de Pesquisa e Ensino em Transportes, XXII, Fortaleza. Anais... Fortaleza: ANPET, 2008, 1081-1092. 
RODRIGUES, M.O. Avaliação do transporte público na cidade de São Carlos. Dissertação (Mestrado). Escola de Engenharia de São Carlos- EESC, São Carlos, 2006.

SANTOS, B. J. R. A qualidade no serviço de transporte público urbano. Disponível em:

<www2.ucg.br/nupenge/pdf/Benjamim_Jorge_r.pdf>. Acesso em 12 jun. de 2008.

SUTHERLAND, S.C. Development Control Plant - Bus Shelters and Saets. Ed. 02. Disponível em:

<www.sutherlandshireconcuncil.com>. Acesso em 30 de maio de 2008.

\section{Dados dos autores:}

Nome completo: Eloisa Maieski Antunes

Filiação institucional: UTFPR

Departamento: DEMINP

Função ou cargo ocupado: Administrativo

Endereço completo para correspondência: Av. Sete de Setembro, 3165, Rebouças. Curitiba -PR. 80230-901

Telefones para contato: (41) 3310-4455

e-mail: eloisa@utfpr.edu.br

Nome completo: Fernanda Antônio Simões

Filiação institucional: UEM

Departamento: PEU

Função ou cargo ocupado: Professora de ensino superior

Endereço completo para correspondência (bairro, cidade, estado, país e CEP): Av. Colombo, 5790 -

Bloco C67 - $2^{\circ}$ Andar.

Telefones para contato: $+\mathbf{5 5}$ (44) 30114052

e-mail: fasimoes@uem.br

Enviado em: 21/05/2012

Aprovado em: 08/04/2013 